\title{
Editorial for \\ the Special Edition on the Years of the Maritime Continent (YMC)
}

The Years of the Maritime Continent (YMC) is a multi-national and multi-year effort, which aims to improve our understanding and prediction skill of the weather and climate system over the Maritime Continent as well as its global impact. YMC has started since July 2017 and consisted of many intensive observations which focus on specific phenomena observed over the MC such as diurnal cycle of rain, cold surges, the Madden-Julian Oscillation (MJO), monsoons, and so on. Although it was originally scheduled to take place until early 2020 , it is now expected to be continued until early 2023, because several intensive observations have been postponed to 2022/2023 due to the COVID-19 pandemic.

YMC adopts a free and open data policy, and requires the field campaign participants to open their quality-controlled data within one year following the completion of each field campaign. By considering the timing of its first dataset release in February 2019, this special edition was proposed to solicit submission of papers which use those data or relevant works which promote the use of data in future.

This special edition was organized jointly with the Scientific Online Letters on the Atmosphere (SOLA), and both journals collect six articles, each. The six papers published in the Journal of the Meteorological Society of Japan (JMSJ) are briefly summarized below.

Two papers discuss data quality control. Geng and Katsumata (2020) developed an algorithm which produces accurate rain rate estimation from polarimetric radar data and verified its validity using the data obtained onboard the research vessel Mirai. Yoneyama et al. (2021) evaluated radiosonde relative humidity data quality and proposed a simple method which can be used to judge whether a correction table of relative humidity data can be used for data taken in other campaigns. Since their works have been applied to the data obtained during the several YMC field campaigns conducted by JAMSTEC, these papers will be a basis of future data usage. Indeed, Geng et al. (2020) used such quality-controlled data obtained onboard the Mirai and discussed an important role of mixed Rossby-Gravity waves on the activity of diurnal cycle of rain over the west coast of Sumatra Island. Diurnal cycle of rain attracts many YMC researchers, and other two papers in this special edition also discussed. Seiki et al. (2021) used satellite and reanalysis products and found diurnally developed convection over the west coast of Sumatra propagated to the eastern Indian Ocean about $500 \mathrm{~km}$ off the coast, and strong diurnal precipitation events often activated synoptic-scale disturbances there. They also discussed its relationship with the MJO. On the one hand, Yulihastin et al. (2022) studied the characteristics of propagation of diurnally developed precipitation events over the northern coastal region of western Java and demonstrated that their behavior was mainly regulated by large-scale prevailing wind patterns. These three papers indicated the important role of scale interaction between diurnal cycle of rain and large-scale disturbances. As for the understanding of large-scale features, Feng et al. (2021) provided a new tool. They demonstrated a capability of the use of zenith wet delay data from the operating Global Positioning System networks as a proxy of precipitable water vapor to study intraseasonal moisture variation over Sumatra. They showed several cases of moisture variation could be explained as a result of tropical-extratropical interaction. Since various in-situ observation datasets have been available from the YMC campaigns, combining routine-based data with those campaign data may lead to further understanding of the moisture variation in detail. So, we can say these six papers have provided not only new knowledge but also keys for future research.

Finally, a unique attempt should be noted. The JMSJ and SOLA including this special edition have joined a cross-organization special collection of the papers on the YMC (COSC; Yoneyama 
and Zhang 2020). Since the YMC deals with various research topics by international communities and their results have been/will be published in many journals, COSC has offered to provide a master list of the entire collection at a single site (https://www.jamstec.go.jp/ymc/) instead of going through each journal of many organizations. Currently, the 21 journals from the seven professional societies have joined the COSC. They are; Earth and Space Science, Geophysical Research Letters, Journal of Advances in Modeling Earth Systems, Journal of Geophysical Research - Atmospheres, Journal of Geophysical Research - Oceans (The American Geophysical Union), Bulletin of the American Meteorological Society, Journal of Climate, Journal of Physical Oceanography, Journal of the Atmospheric Sciences, Monthly Weather Review, Weather and Forecasting (The American Meteorological Society), Journal of Southern Hemisphere Earth Systems Science (The Australian Meteorological and Oceanographic Society), Terrestrial, Atmospheric and Oceanic Sciences (The Chinese Geoscience Union), Atmospheric Chemistry and Physics, Nonlinear Processes in Geophysics, Ocean Science (The European Geosciences Union), Journal of the Meteorological Society of Japan, Scientific Online Letters on the Atmosphere (The Meteorological Society of Japan), Atmospheric Science Letters, International Journal of Climatology, and Quarterly Journal of the Royal Meteorological Society (The Royal Meteorological Society). The COSC collects papers submitted to the above-mentioned journals by December 2025. Thus, while the JMSJ and SOLA joint special edition has been completed, both will continue to collect papers related to the YMC as a part of COSC under the regular peer-review processes. This joint edition played a role of kicking-off this unique collection. In addition, we believe many papers will follow.

January 2022

Kunio Yoneyama, Guest Chief Editor

\author{
Editorial Board Members of the YMC Special Edition \\ Kunio Yoneyama (Japan Agency for Marine-Earth Science and Technology) Guest Chief \\ Editor \\ Manabu D. Yamanaka (Research Institute for Humanity and Nature) Co-chief Editor \\ Kazuaki Yasunaga (University of Toyama) Co-chief Editor \\ Tomoe Nasuno (Japan Agency for Marine-Earth Science and Technology) \\ Shin-Ya Ogino (Japan Agency for Marine-Earth Science and Technology) \\ Kelvin J. Richards (University of Hawai' i / International Pacific Research Center) \\ Ryuichi Shirooka (Japan Agency for Marine-Earth Science and Technology) \\ Tetsuya Takemi (Kyoto University) \\ Hiroyuki Yamada (University of the Ryukyus) \\ Shigeo Yoden (Kyoto University) \\ Chidong Zhang (National Oceanic and Atmospheric Administration / Pacific Marine \\ Environmental Laboratory)
}

\section{References}

Feng, L., T. Zhang, T.-Y. Koh, and E. M. Hill, 2021: Selected years of monsoon variations and extratropical dryair intrusions compared with the Sumatran GPS Array observations in Indonesia. J. Meteor. Soc. Japan, 99, 505-536.

Geng, B., and M. Katsumata, 2020: An algorithm for detecting and removing the spurious differential phase observed by C-band polarimetric radar in the rain. $J$. Meteor. Soc. Japan, 98, 585-613.
Geng, B., M. Katsumata, and K. Taniguchi, 2020: Modulation of the diurnal cycle of precipitation near the southwestern coast of Sumatra by mixed Rossbygravity waves. J. Meteor. Soc. Japan, 98, 463-480.

Seiki, A., S. Yokoi, and M. Katsumata, 2021: The impact of diurnal precipitation over Sumatra Island, Indonesia, on synoptic disturbances and its relation to the Madden-Julian Oscillation. J. Meteor. Soc. Japan, 99, $113-137$.

Yoneyama, K., and C. Zhang, 2020: Years of the Maritime Continent. Geophys. Res. Lett., 47, e2020GL087182, 
doi:10.1029/2020GL087182.

Yoneyama, K., M. Fujita, A. Seiki, R. Shirooka, S. Yokoi, E. O. Cayanan, C. O. Iglesia, and O. C. Cabrera, 2021: Evaluation of LMS6 and RS41 radiosonde humidity data obtained during YMC-Boreal Summer Monsoon study in 2018 and 2020. J. Meteor. Soc. Japan, 99,
1115-1125.

Yulihastin, E., T. W. Hadi, M. R. Abdillah, I. R. Fauziah, and N. S. Ningsih, 2022: Propagation of convective systems associated with early morning precipitation and different northerly background winds over western Java. J. Meteor. Soc. Japan, 100, 99-113. 